\title{
Surface Imprinting of Silica Gel by Methyldopa and Its Application in the Solid Phase Extraction Procedure
}

\author{
Mohammad Taghi Vardini* and Leila Mardani \\ Department of Chemistry, Tabriz Branch, Islamic Azad University, Tabriz, Iran
}

\begin{abstract}
An imprinted amino-functionalized silica gel material was prepared by surface molecular imprinting technique combined with a sol-gel process on the supporter of activated silica gel and used as a solid-phase extraction for the extraction and determination of methyldopa (MTD). Non-imprinted silica adsorbent was synthesized without the addition of MTD using the same process. MTD-imprinted and non-imprinted silica adsorbents were characterized by scanning electron microscopy (SEM), Fourier transform infrared (FTIR) spectroscopy and the static adsorption experiments. The prepared MTD-imprinted silica sorbent demonstrated high adsorption capacity and significant selectivity for MTD in the presence of competitive substances. The maximum adsorption capacity of surface imprinted and non-imprinted silica adsorbent for MTD were 14565.81 and $2990.56 \mu \mathrm{g} \mathrm{g}^{-1}$, respectively. The imprinted 3-aminopropyl triethoxysilane (APS) modified silica gel adsorbent provided fast kinetics for the adsorption of MTD. In the operational mode of solid phase extraction (SPE), calibration curve of MTD solution was linear in the range of about 15 to $100 \mu \mathrm{gL}^{-1}$. The limit of detection (LOD) and precision (RSD) during five replicates were $2.31 \mu \mathrm{g} \mathrm{mL}^{-1}$ and $5.69 \%$, respectively. At last, the MTD-imprinted material was used as SPE adsorbent to determine the MTD in non-spiked and spiked pharmaceutical samples with satisfactory recovery higher than $94 \%$.
\end{abstract}

Keywords: molecularly imprinted polymer (MIP), sol-gel, solid phase extraction (SPE), methyldopa (MTD)

\section{Introduction}

Sample preparation techniques prior to measure organic chemicals such as drugs in biological and environmental matrices have been as challenging and exciting tasks in recent years. Hence, it is generally accepted that the most important step in analytical methods is sample preparation. On the other, in recent years more and more stringent regulations related to quality control of drugs conducted to demands on the ease and speed analysis. ${ }^{1}$

Molecularly imprinted polymers (MIPs) are synthetic materials, in which a lot of cavities specifically designed to target molecule (i.e., template molecule) are distributed and complementary in shape, size and functional groups to the target molecule. Therefore, MIPs have specific molecular recognition and high binding affinity for the target molecule, and are described as synthetic antibodies or receptors. ${ }^{2,3}$ Recently, MIPs, as highly selective solid adsorbents, have been widely used in various fields, such

*e-mail: mtvardini@iaut.ac.ir as separation and preconcentration, manufacturing of sensors, the stationary phases for chromatography, pseudo immunoassay, catalysis and others..$^{2-9}$ In particular, new method of molecularly imprinted solid phase extraction (SPE), in which the MIP-solid adsorbent can selectively extract, has attracted much attention in the separation and enrichment area. ${ }^{6,10-12}$

The usual method for preparing MIPs, the entrapping way, has some disadvantages, such as time-consuming and complicated preparation method, less recognition sites within the matrix polymer particles obtained by crushing and grinding imprinted polymeric monolith, and greater diffuse barrier for the template molecules coming from matrix thickness, resulting in poor binding capacity and lower binding kinetics of MIPs to the template molecule. ${ }^{13,14}$ In order to overcome these disadvantages, the method of surface-imprinting was developed and put toward as a new molecular imprinting technique: $2,3,6,15$ (i) pre-grafting of functional polymers in the form of a thin layer (in the manner of "grafting from" or "grafting to") on the surface of silica gel particles; (ii) adsorption of the template molecule towards grafted particle is saturated 
by the intermolecular interactions; (iii) post-imprinting of template molecule is associated with the use of specific cross-linking agent that has two reactive end groups. After removal of the template molecule, a mass of the imprinted caves able to recognize and re-bind the template molecules is left and distributed in the thin polymer layer, resulting in imprinted material with high performance such as more accessible sites, fast mass transfer and high recognition and binding ability to template molecule. This new method of surface imprinting is more based on the interactions between the grafted functional polymer and template molecule, than based on the interactions between functional monomers and template molecules, such as the conventional imprinting method, and this is a clear difference between the two methods. In this study, silica gel was used as support for organic group because it is a non-swelling inorganic material and stable under acidic conditions, it has high mass transfer features and very high thermal resistance.

MTD ( $\alpha$-methyl-3,4-dihydroxyphenylalanine) is a catechol derivative (catecholamine) widely used as an antihypertensive agent (Figure 1). MTD is a centrally alpha ${ }_{2}$-adrenoreceptor agonist acting, which decreases the sympathetic one and blood pressure. ${ }^{16,17}$ Several analytical methods for quantitative determination of MTD in pharmaceutical formulations has been reported. They involve titrimetry, ${ }^{18}$ fluorimetry, ${ }^{19}$ amperometry, ${ }^{20}$ gas chromatography, ${ }^{21}$ high-performance liquid chromatography (HPLC), ${ }^{22}$ chemiluminescence,,$^{23}$ voltammetry ${ }^{24}$ and spectrophotometry. ${ }^{25,26}$ Some of these methods are not simple, some are time-consuming or involve processes with precise control of experimental conditions or suffer interference from tablet matrix and, therefore, not suitable for routine analysis. Often reported titrimetric methods were indirect titrations and based on the reduction reactions, which is already involved in unsaturated organic compounds. Official non-aqueous titration method reported in USP2 described how to measure the MTD. ${ }^{18,27}$

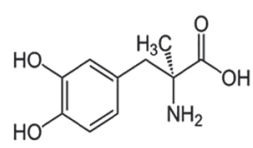

Figure 1. Structure of methyldopa.

The aim of this study was to prepare a new and simple molecularly imprinted amino-functionalized silica gel adsorbent by a surface imprinting technique for use in SPE procedure to determine the MTD in pharmaceutical samples. The proposed method provided high selectivity and adsorption capacity for MTD.

\section{Experimental}

\section{Materials and chemicals}

Silica gel as the supporter (with particle size of 2-25 $\mu \mathrm{m}$ ) to provide functionalized imprinted adsorbent, methyldopa, 3-aminopropyl triethoxysilane (APS), tetraethoxy silicane (TEOS), acetic acid (HAc), methanol, hydrochloric acid, phosphoric acid and sodium dihydrogen phosphate were purchased from Merck (Darmstadt, Germany). All reagents were of analytical grade or their equivalent. Commercial pharmaceutical samples containing $250 \mathrm{mg}$ MTD per unit were purchased from local pharmacies in Tabriz, Iran. MTD structure was shown in Figure 1. HPLC mobile phase was a mixture of methanol and $\mathrm{pH} 2.88$ phosphate buffer $(92: 8, \mathrm{v} / \mathrm{v})$.

\section{Instrumentation}

Fourier transform infrared (FTIR) spectra were recorded with Shimadzu FTIR spectrometer (F8400, Japan). Surface morphology of the synthesized particles was observed using scanning electron microscopy (SEM, Vega-Tescan). Determination of MTD was made by double beam spectrophotometer-UV-Vis (UV-1800, Shimadzu, Japan) at a wavelength of $280 \mathrm{~nm}$. UV-Vis absorption spectra of MTD were recorded by a UV-1800 spectrophotometer (Shimadzu, Japan). HPLC chromatography system includes a PerkinElmer 200 Series workstation and UV-Vis detector. All HPLC separations were run on an analytical reverse phase ODS column (length $300 \mathrm{~mm}$, internal diameter of $4.6 \mathrm{~mm}$, particle size $5 \mu \mathrm{m}$ ) with a flow rate of $1.5 \mathrm{~mL} \mathrm{~min}^{-1}$ at room temperature.

Preparation of the MTD-imprinted amino-functionalized silica gel

For obtaining the activated silica gel surfaces, a mixture of $100 \mathrm{~mL}$ hydrochloric acid $\left(6 \mathrm{~mol} \mathrm{~L}^{-1}\right)$ and $10.0 \mathrm{~g}$ of silica gel was refluxed under stirring for $8 \mathrm{~h}$, then the blend was filtered and washed with pure distilled water to neutralize and dried under vacuum condition at $68^{\circ} \mathrm{C}$ for $8 \mathrm{~h}$.

To provide the MTD-imprinted functionalized sorbent, $0.5 \mathrm{~g}$ of MTD was dissolved in $5 \mathrm{~mL}$ of acidified methanol $\left(0.01 \mathrm{~mol} \mathrm{~L}^{-1} \mathrm{HCl}\right)$ under stirring condition then neutralized with $\mathrm{NaOH}\left(0.01 \mathrm{~mol} \mathrm{~L}^{-1}\right)$. After addition of $5 \mathrm{~mL}$ of APS, the solution was refluxed for $30 \mathrm{~min}$. Then the mixture of $10 \mathrm{~mL}$ of TEOS and $4.0 \mathrm{~g}$ of activated silica gel was added into this solution and stirred for $5 \mathrm{~min}$. After addition of $1 \mathrm{~mL}$ $\mathrm{HAc}\left(2.0 \mathrm{~mol} \mathrm{~L}^{-1}\right)$, the mixture was stirred for $15 \mathrm{~h}$ at room temperature. The product was dried at $100{ }^{\circ} \mathrm{C}$ for $12 \mathrm{~h}$ and 
mixed with $25 \mathrm{~mL}$ methanol and $25 \mathrm{~mL}$ of $1.0 \mathrm{~mol} \mathrm{~L}^{-1} \mathrm{HCl}$ under stirring for $3 \mathrm{~h}$ to omit MTD. The resulting product was washed with $50 \mathrm{~mL}$ of the mixture of methanol and $6 \mathrm{~mol} \mathrm{~L}^{-1}$ $\mathrm{HCl}(1: 1, \mathrm{v} / \mathrm{v})$ and pure distilled water, then neutralized with $0.05 \mathrm{~mol} \mathrm{~L}^{-1} \mathrm{KOH}$ and washed by pure distilled water again. Finally, the sorbent was washed with pure methanol and dried at $85^{\circ} \mathrm{C}$ for $12 \mathrm{~h}$. For comparison, a blank silica adsorbent was prepared by the same procedure, only without using the template molecule in the preparation process. ${ }^{3,6}$

\section{Binding experiments}

FTIR spectroscopy and static adsorption method were used for the characterization of proposed surface imprinted silica sorbent. The imprinted and non-imprinted adsorbents $(50 \mathrm{mg})$ were added into the solutions of MTD in $25 \mathrm{~mL}$ methanol with initial concentration of MTD ranging 0-35 $\mu \mathrm{g} \mathrm{mL}^{-1}$. After incubation at room temperature for $75 \mathrm{~min}$ and centrifugation of the mixtures, the concentration of free MTD in the supernatants was measured by UV-Vis at $280 \mathrm{~nm}$. The amount of MTD bound to the surface of imprinted and non-imprinted silica gels were calculated by subtracting the amount of free MTD in the supernatants from the amount of MTD initially added. Similarly, in kinetic adsorption experiments, the adsorption dynamics of the imprinted and non-imprinted was performed by detecting the free MTD concentration in the supernatants at the different adsorption regular time intervals. In summary, $50 \mathrm{mg}$ of imprinted or non-imprinted silica sorbents were mixed with $25 \mathrm{~mL}$ of MTD methanol solution at a concentration of $30 \mu \mathrm{g} \mathrm{mL}^{-1}$ and incubated at regular intervals. Then the supernatant and the adsorbents were separated by centrifugation and the concentration of MTD in supernatant was measured using UV-Vis spectrophotometric analysis.

In experiments of steady-state binding with a stable state, in short, $50 \mathrm{mg}$ of imprinted or non-imprinted silica sorbents were mixed with $25 \mathrm{~mL}$ of methanol solution of MTD in concentrations ranging from 0 to $35 \mu \mathrm{g} \mathrm{mL}^{-1}$. Imprinted or non-imprinted materials were separated by centrifugation after incubation for $75 \mathrm{~min}$ at room temperature. The amount of MTD bound to adsorbents was determined using UV-Vis spectrophotometry. The adsorption capacity (Q) was calculated using the following equation $1:{ }^{11,28}$

$\mathrm{Q}=\frac{\left(\mathrm{C}_{\mathrm{i}}-\mathrm{C}_{\mathrm{f}}\right) \mathrm{V}}{\mathrm{W}}$

where, $\mathrm{C}_{\mathrm{i}}$ and $\mathrm{C}_{\mathrm{f}}$ represent the initial and equilibrium concentration of methyldopa $\left(\mu \mathrm{gLL}^{-1}\right), \mathrm{W}$ is the weight of the adsorbents ( $\mathrm{mg}$ ) and $\mathrm{V}$ is the volume of the methyldopa solutions $(\mathrm{mL})$.

\section{SPE procedure for extraction of MTD}

The adsorption of MTD from the solutions was studied in SPE mode. Glassy columns with i.d. $1 \mathrm{~cm}$ were packed with $300 \mathrm{mg}$ of dry blank and imprinted materials and washed 3-4 times with $0.01 \mathrm{~mol} \mathrm{~L}^{-1} \mathrm{HCl}$. Then $0.01 \mathrm{~mol} \mathrm{~L}^{-1} \mathrm{NaOH}$ and pure distilled water were used for neutralizing the packed column. Before passing sample solution, $1 \mathrm{~mL}$ pure methanol should pass through the column for conditioning the solid phases. Experiments consisted of loading $5 \mathrm{~mL}$ of MTD solution in methanol (typically $10-60 \mu \mathrm{g} \mathrm{mL}^{-1}$ ) onto each column and washing with at least $2.5 \mathrm{~mL}$ of methanol and then elution with at least $5 \mathrm{~mL}$ of elution solvent $\left(0.01 \mathrm{~mol} \mathrm{~L}^{-1} \mathrm{HCl}\right)$. Various breakthrough, washing and elution solvents were collected and analyzed by UV-Vis spectrophotometric method. The extraction percent, $\% \mathrm{E}$, was calculated using the equation $2: 11,28$

$E(\%)=\frac{C_{i}-C_{f}}{C_{i}} \times 100$

Study of adsorbent composition effect on the extraction efficiency of MTD

For this purpose, SPE column was filled by $300 \mathrm{mg}$ imprinted silica and $5 \mathrm{~mL}$ of the MTD methanol solution with concentration of $70 \mu \mathrm{g} \mathrm{mL}-1$ passed through the column with flow rate of $5 \mathrm{~mL} \mathrm{~min}^{-1}$. Then SPE column was eluted using stripping aqueous solution of $0.01 \mathrm{~mol} \mathrm{~L}^{-1} \mathrm{HCl}$ with

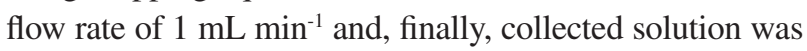
analyzed by UV-Vis spectrophotometric method at $\lambda 280 \mathrm{~nm}$.

\section{Evaluation of analytical performance}

For the evaluation of analytical performance under the SPE circumstances mentioned above, the experimental procedures are explained as follows: in order to examine the breakthrough volume, the different volume solutions with a certain amount of MTD $(50 \mu \mathrm{g})$ were passed via column and the absorbance of MTD in the effluent measured. Based on this, the adsorption capacities of surface imprinted and non-imprinted materials were calculated. For the investigation of calibration curve, solutions with MTD concentrations of 0.5 to $120 \mu \mathrm{g} \mathrm{mL}-1$ were used and the limit of detection (LOD) of MTD was determined based on $3 \sigma / \mathrm{m}$ ( $\sigma$ and $\mathrm{m}$ are blank standard deviation and calibration curve slope, respectively) using UV-Vis detector. 
Preparation of drug sample solutions

Ten tablets of commercial brand of MTD were weighed and finely powdered. A part of the powder, equivalent to $0.0021 \mathrm{~g}$, was accurately weighed and dissolved in $5 \mathrm{~mL}$ of solvent by shaking for $15 \mathrm{~min}$. The resulting mixture was transferred to a $10 \mathrm{~mL}$ standard flask and the volume completed with methanol. Definite volumes of this solution were used to prepare dilute solutions. A fraction of the final solution was taken for extraction and analysis according to the recommended approach.

\section{Results and Discussion}

\section{Preparation of MTD-imprinted silica gel sorbent}

The matrix of elementary particles of silica gel consists of a core with silicon atoms connected to oxygen atoms via siloxane bonds (bonds of silicon-oxygen-silicon). On the surface of each primary particle, some uncondensed residual hydroxyl groups of the main polymer silicic acid remain. The remaining hydroxyl groups on the silica gel share their polar properties. The hydroxyl groups react with the silane reagents to form bonded phases. The complex surface of silica includes two types of hydroxyl groups: severely bound to chemically adsorbed water and loosely bound to physically adsorbed water.,.$^{2,6,10-12}$ In this study, APS functional monomer interacts with the carboxyl, hydroxyl and amino groups of MTD. The complex was formed between MTD and APS, then co-hydrolyzed and cocondensed with silanol groups. Figure 2 shows preparation steps of MTD-imprinted silica adsorbent. Strong hydrogen bonds were organized between amino groups of APS and functional groups of MTD. TEOS acts as a cross-linker to create polymer frame so that makes the stability of the recognition sites. HAc was added as activator to enable high-speed formation of the polymer. ${ }^{15}$ Thus, surface of the activated silica gel was grafted with the complex of MTD and APS, not only free APS. MTD was removed by concentrated $\mathrm{HCl}$ (in methanol) and the custom made holes to the MTD remained on the surface of silica gel adsorbent. ${ }^{10}$

\section{Characterization of MTD-imprinted silica gel sorbent}

\section{Characteristic of the FTIR spectra}

To recognize the presence of APS in functionalized silica gel sorbent, FTIR spectra were obtained from methyldopa, activated silica gel, non-imprinted and hydrolyzed MTD-imprinted-amino functionalized silica gel sorbents (Figure 3). The presence of absorption peaks at

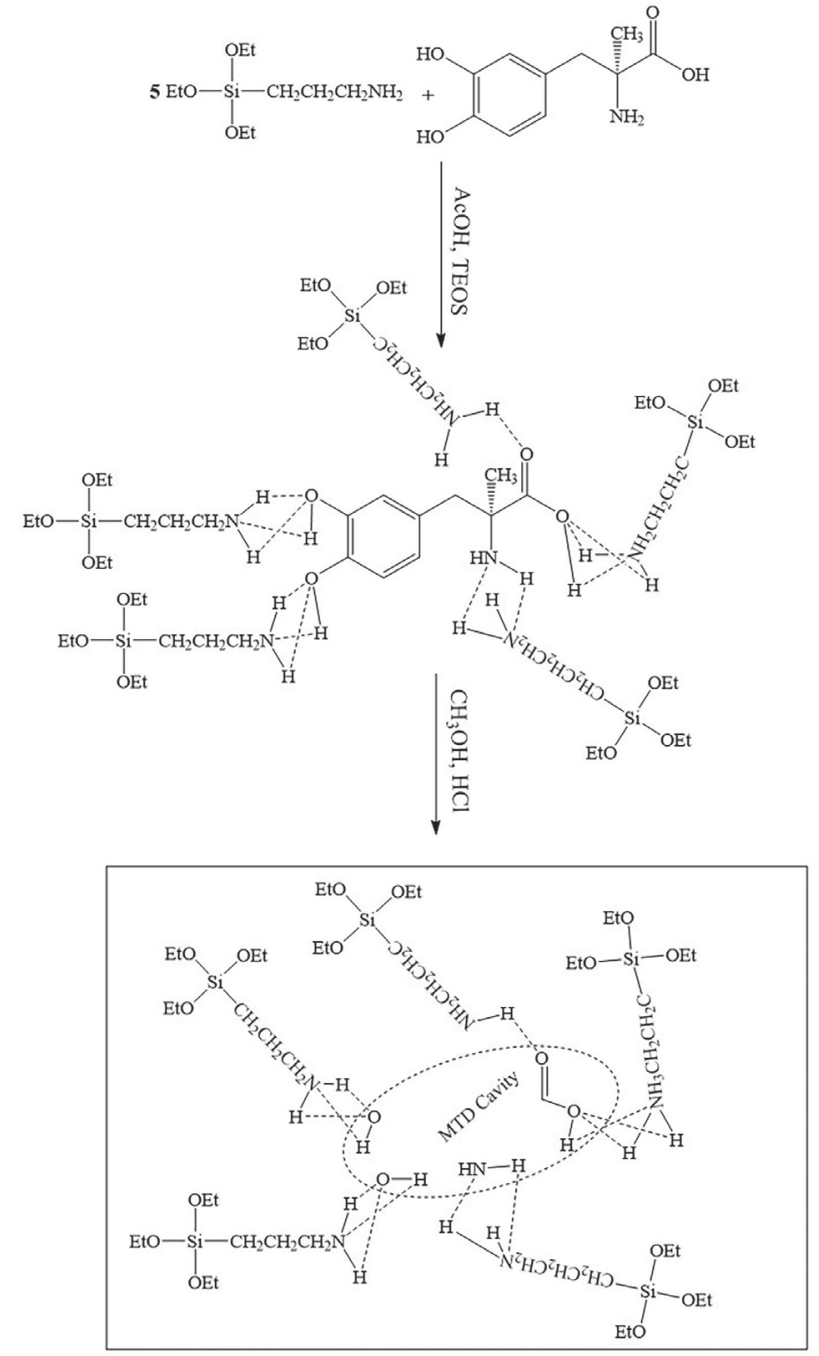

Figure 2. Preparation protocol of the MTD-imprinted silica sorbent.

$3200-3700 \mathrm{~cm}^{-1}$ was expressed by $\mathrm{OH}$ vibration. This showed that the silica gel has been activated by the concentrated $\mathrm{HCl}$ solution..$^{29,30}$ As shown in Figure 3, features observed around 1072 and $964 \mathrm{~cm}^{-1}$ demonstrated Si-O-Si and $\mathrm{Si}-\mathrm{OH}$ vibrations, respectively. The bands in about 794 and $462 \mathrm{~cm}^{-1}$ were obtained from $\mathrm{Si}-\mathrm{O}$ vibration. As can be seen in MTD's IR spectrum (Figure 3a), there were peaks in 1475 and $1600 \mathrm{~cm}^{-1}$ related to benzene ring, in $3400 \mathrm{~cm}^{-1}$ regarding $\mathrm{OH}$ vibration of phenol, 3300 and $3400 \mathrm{~cm}^{-1}$ related to $\mathrm{N}-\mathrm{H}$ vibrations. The features in 1527 and $1634 \mathrm{~cm}^{-1}$ indicated the presence of $\mathrm{NH}_{2}$-APS interactions in the imprinted sorbent. Deletion of the latter two bands in the non-imprinted sorbent spectrum happened because of absence hydrogen bonds between MTD and APS during the preparation procedure of non-imprinted silica gel (Figure 3d).

\section{Study of surface morphology}

To survey the surface of adsorbents, the SEM images were used. SEM images related to activated silica gel, 


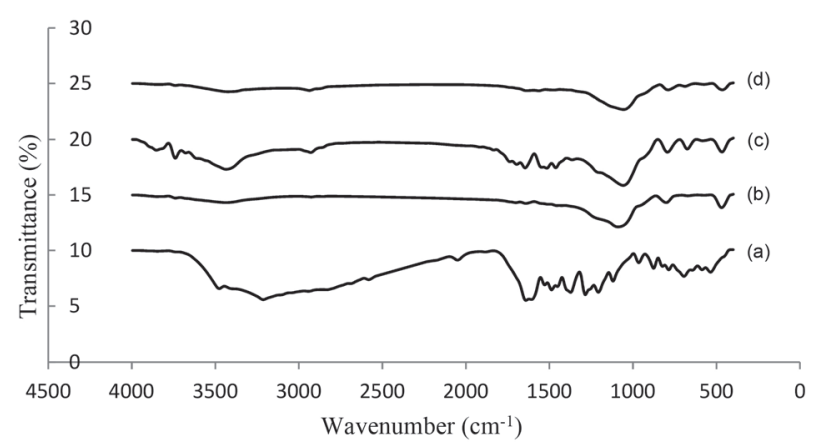

Figure 3. FTIR spectra of (a) methyldopa; (b) activated silica gel; (c) imprinted and (d) non-imprinted sorbents.

imprinted and non-imprinted materials were shown in Figure 4. As is clear from the image of activated silica gel, a relatively smooth surface has been achieved. With the introduction of MTD into silica gel structure, adsorbent surface was changed and uneven surface was obtained. This rough surface was due to the presence of template molecule.

\section{Characterization by binding experiment}

The profile of kinetic for the imprinted and non-imprinted silica gel adsorbent was evaluated at a concentration of $15 \mu \mathrm{g} \mathrm{mL} \mathrm{m}^{-1} \mathrm{MTD}$ and is shown in Figure 5a. It was very obvious that a significant adsorption equilibrium on MTD-imprinted and non-imprinted silica sorbent occurred within 75 min without any significant change in terms of adsorption after that. Compared to non-imprinted adsorbent, the adsorption capacity for MTD binding on imprinted one is much higher. This suggests that a molecular imprinting process has resulted in the formation of specific recognition sites on the surface of the MTD absorbent.

Adsorption capacity is an important factor because it determines how much adsorbent is needed to quantify the analyte concentration of a given solution. Adsorption capacity was tested following the mentioned general procedure. As can be seen in Figure 5b, the amount of adsorbed MTD per adsorbent weight unit increased with initial concentration of MTD. The initial MTD concentration was increased until the plateau value of adsorption capacity. The static adsorption capacity of the imprinted and non-imprinted sorbent for MTD was calculated as 14565.81 and $2990.56 \mu \mathrm{g} \mathrm{g}^{-1}$, respectively. The static adsorption capacity of the imprinted silica gel sorbent was about 15 times of non-imprinted one. The results showed that the surface imprinted silica sorbent has a high adsorption capacity for MTD.

\section{Application of MTD-imprinted silica gel for the SPE of MTD}

SPE and recognition of MTD is often considered to be a large cost advantage in deploying their applications. The SPE procedure includes the MTD loading $(5 \mathrm{~mL}$ solution of 20-100 $\mu \mathrm{g} \mathrm{mL}^{-1} \mathrm{MTD}$ ) onto the SPE's column, washing the column and then eluting MTD in a small volume. Experiments using methanol as washing solvent and $\mathrm{HCl}$ solution (0.01 mol L-1) as eluting solvent (Table 1) stated that MTD was kept by MTD-imprinted silica gel and eluted by the elution solvent. After each use for regenerating imprinted binding cavities, MTD-SPE column was again washed by methanol $\left(0.01 \mathrm{~mol} \mathrm{~L}^{-1} \mathrm{HCl}\right)$ then it was neutralized with $\mathrm{NaOH}$ solution. Finally it was washed with methanol only. The optimization processes in the application of imprinted silica gel as SPE sorbent are listed as follows.

\section{Optimization of the extraction conditions}

\section{$\mathrm{pH}$ effect}

The effect of sample $\mathrm{pH}$ on the extraction of $500 \mu \mathrm{g}$ MTD from methanol solutions by imprinted silica gel adsorbent column was studied at the $\mathrm{pH}$ range of 3 to 8 . The sample $\mathrm{pHs}$ were adjusted with dilute solutions of $\mathrm{HCl}$ or $\mathrm{NaOH}$. The optimized extraction of MTD by SPE column was seen at $\mathrm{pH}$ around 8.0 and low efficiency of the MTD adsorption was observed below pH 7.0. As can be seen in Table 1, adsorption of MTD on the imprinted silica gel was affected by the $\mathrm{pH}$ of samples. In high
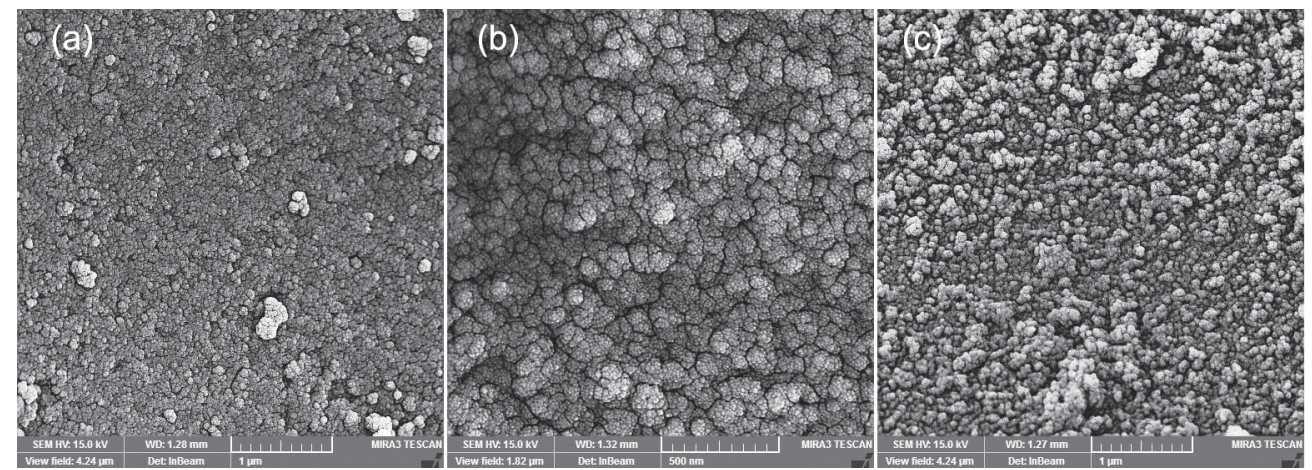

Figure 4. SEM images for (a) activated silica gel, (b) non-imprinted and (c) surface imprinted silica gel. 

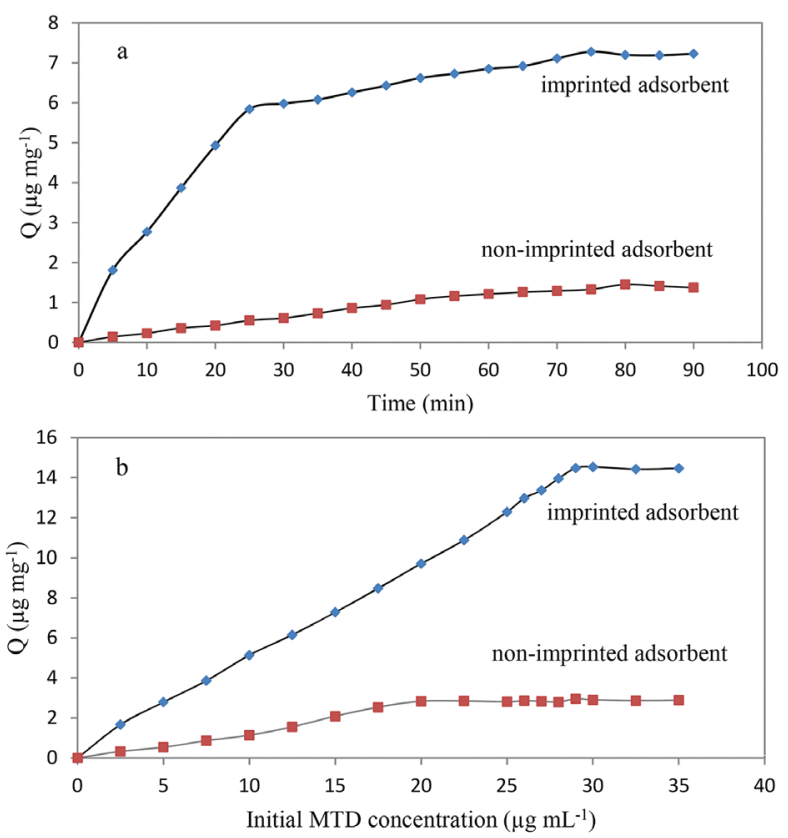

Figure 5. Binding experiments; (a) adsorption kinetics for imprinted and non-imprinted adsorbents with initial concentration of MTD $30 \mu \mathrm{g} \mathrm{mL}{ }^{-1}$; (b) loading isotherms of MTD onto the imprinted and non-imprinted adsorbents during constant time of 75 min. (Constant volume of MTD solutions, $25 \mathrm{~mL}$; constant amount of adsorbents, $50 \mathrm{mg}$ ).

pHs (above 8), resonance of the phenyl ring in MTD structure occurred with two hydroxyl groups. To avoid this reactivity of MTD, the sample $\mathrm{pH}$ was kept below 8.0 for further studies.

\section{Effect of adsorbent composition on the extraction efficiency of MTD}

Number and quality of the MIP recognition sites are highly dependable on the molar relationship between template and functional monomer. In this study, surfaceimprinted silica sorbents were prepared applying different mole ratios of APS to MTD. Figure 6 shows the recovery efficiencies acquired by these adsorbents that filled SPE columns. The recovery efficiency increases continuously reaching a maximum at 20 molar ratio of APS to MTD. The higher molar ratio of 20 was not applied because it is likely that the selectivity of CNTs-MIPs was strongly reduced.

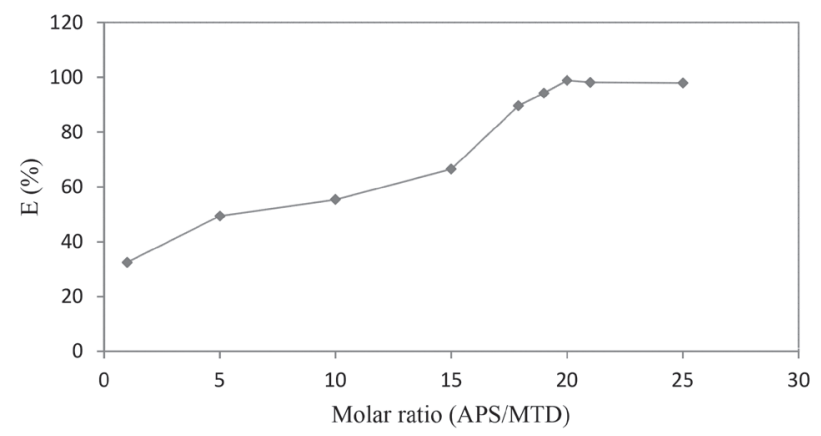

Figure 6. The effect of molar ratio of functional monomer to template in the synthesis procedure on the extraction efficiency of MTD by surface imprinted silica gel as SPE adsorbent.

Effect of sample flow rate and adsorbent amount in SPE column

The effect of the sample flow rate on the MTD extraction was examined in the rate of $2-15 \mathrm{~mL} \mathrm{~min}^{-1}$ at $\mathrm{pH}$ 8.0. The flow rates that MTD extraction would be optimized were up to $5 \mathrm{~mL} \mathrm{~min}^{-1}$. At higher flow rates, the efficiency of MTD extraction has fallen to $40 \%$. Solution of MTD was balanced faster with imprinted silica gel in mean flow rate. Increasing amount of surface imprinted silica gel in SPE column raised the extraction efficiency. That was because of increasing number of cavity sites, but if the amount of adsorbent was greater than $300 \mathrm{mg}$ extraction, the efficiency would decrease. This decrease was due to diminishing sample passing speed.

Table 1. Recoveries (\%) of MTD using $\mathrm{HCl}$ (in water) solutions as eluting solvents after SPE procedure based on proposed adsorbents

\begin{tabular}{lcccccccccc}
\hline & $\begin{array}{c}\text { Eluting } \\
\text { solvent }\end{array}$ & \multicolumn{2}{c}{$\mathrm{HCl}(0.0001 \mathrm{~mol} \mathrm{~L}-1)$} & $\mathrm{HCl}\left(0.001 \mathrm{~mol} \mathrm{~L}^{-1}\right)$ & & $\mathrm{HCl}\left(0.01 \mathrm{~mol} \mathrm{~L}^{-1}\right)$ & $\mathrm{HCl}\left(0.1 \mathrm{~mol} \mathrm{~L}^{-1}\right)$ \\
\cline { 2 - 9 } & $\begin{array}{c}\text { SPE } \\
\text { adsorbent }\end{array}$ & Imprinted & Non-imprinted & Imprinted & Non-imprinted & Imprinted & Non-imprinted & Imprinted & Non-imprinted \\
\hline 3 & & $14.97(6.25)$ & $1.63(9.75)$ & $27.33(6.54)$ & $3.90(7.35)$ & $45.60(6.31)$ & $2.92(7.68)$ & $46.90(6.44)$ & $3.15(7.73)$ \\
4 & $16.75(5.85)$ & $3.50(8.65)$ & $35.23(7.65)$ & $6.80(8.29)$ & $59.22(3.63)$ & $13.12(8.62)$ & $55.30(8.15)$ & $12.70(9.43)$ \\
5 & & $23.92(7.38)$ & $4.86(8.47)$ & $46.62(7.55)$ & $8.47(9.12)$ & $67.63(4.70)$ & $11.63(6.37)$ & $66.11(6.57)$ & $12.42(8.72)$ \\
6 & $32.20(7.03)$ & $7.73(8.05)$ & $54.77(6.61)$ & $11.97(9.42)$ & $78.50(4.95)$ & $14.40(6.77)$ & $77.20(4.93)$ & $13.75(7.29)$ \\
7 & $44.13(6.86)$ & $10.86(8.78)$ & $56.10(5.63)$ & $14.45(7.45)$ & $83.15(2.55)$ & $19.50(9.22)$ & $79.86(3.70)$ & $19.87(7.86)$ \\
8 & $48.65(5.69)$ & $13.43(9.25)$ & $63.92(4.92)$ & $17.23(6.93)$ & $98.42(1.99)$ & $22.20(8.27)$ & $97.56(3.22)$ & $23.61(8.14)$ \\
\hline
\end{tabular}

Average of five measurements with RSD (\%) in parenthesis. Sample conditions: volume, $5 \mathrm{~mL}$; solvent, methanol; MTD concentration, 70 $\mu \mathrm{g} \mathrm{mL}{ }^{-1}$. SPE conditions: amount of adsorbents in SPE column, $300 \mathrm{mg}$; sample flow rate, $5 \mathrm{~mL} \mathrm{~min}^{-1}$; elution flow rate, $1 \mathrm{~mL} \mathrm{~min}^{-1}$; all determinations were accomplished with UV-Vis method at $\lambda 280 \mathrm{~nm}$. 
Type of elution solvent

The adsorbed MTD can be eluted from the MIPs using mineral acids. Since methyldopa forms hydrogen bonds with functional groups on binding sites of MIPs, various concentrations of hydrochloric acid (0.0001-0.1 mol L-1) were tested for their ability to remove MTD from the adsorbent material. The best concentration of $\mathrm{HCl}$ solution used for the elution of the analyte from the MIPs and the results of the recovery are given in Table 1 . It is worth noting that the difference in MTD recovery on the adsorbent by solutions of 0.01 and $0.1 \mathrm{~mol} \mathrm{~L}^{-1} \mathrm{HCl}$ were not statistically significant.

Interference of co-existing foreign and structurally similar substances

Different compounds often present in pharmaceutical sample were examined for their effect on the adsorption of MTD onto surface-imprinted adsorbent. The choice of interferents was also based on their affinity for the surface imprinted silica and the effect on the analytical signal of MTD measured by UV-Vis spectrophotometry. In the presence of the excess of uric acid, glucose, sucrose, $\mathrm{PO}_{4}^{3-}, \mathrm{CO}_{3}^{2-}, \mathrm{SO}_{4}^{2-}, \mathrm{NO}_{3}^{-}, \mathrm{Cl}^{-}, \mathrm{Fe}^{3+}, \mathrm{Mg}^{2+}, \mathrm{Ca}^{2+}, \mathrm{Na}^{+}$and $\mathrm{K}^{+}$, the relative absorbance of MTD was in the range of about $90-97 \%$ compared with the standard solution of MTD. The interfering substances were added separately in the concentration range of $1-50000 \mu \mathrm{g} \mathrm{mL}^{-1}$ to the MTD solution $\left(70 \mu \mathrm{g} \mathrm{mL}^{-1}\right)$ and extraction procedure was used. The tolerable concentration of any foreign substance was taken as the largest amount, yielding an error below $10 \%$ in the extraction efficiency of the MTD. As can be seen in Table 2, the results showed that the tolerable concentration ratios of interferences were over 700 for $\mathrm{NO}_{3}^{-}, \mathrm{Cl}^{-}, \mathrm{SO}_{4}^{2-}, \mathrm{Na}^{+}, \mathrm{K}^{+}, \mathrm{Ca}^{2+} ; 400$ for $\mathrm{PO}_{4}^{3-}, \mathrm{CO}_{3}^{2-}, \mathrm{Fe}^{3+}$, $\mathrm{Mg}^{2+} ; 150$ for uric acid, glucose and sucrose. It should be noticed that after required dilutions of real samples, effects of possible interferences may have overlooked. Therefore, the interferences caused by dopamine and epinephrine as the structurally similar compounds was also studied. It was found that the tolerable concentration ratios were over 50 for dopamine and 15 for epinephrine. As a result, the values in Table 2 indicate that the MTD-imprinted silica adsorbent has high selectivity for MTD over the co-existing foreign and structurally similar compounds.

\section{Analytical performance and application}

Total retention of MTD was obtained onto surface-MIPs with repeatability better than 5\%. MTD recovery of about 90-100\% was with repeatability of the elution process below $5 \%$ (Table 1). The breakthrough volume of the prepared adsorbent was determined by passing the solution of MTD $(50 \mu \mathrm{g})$ via the column filled with $300 \mathrm{mg}$ of the surface-MIPs and measuring of the absorbance of MTD in the effluent. The experiment ended when the extraction efficiency of MTD decreased to $90 \%$. According to this, the capacity of proposed surface imprinted adsorbent for MTD was calculated as $458.24 \mu \mathrm{g} \mathrm{g}^{-1}$. Non-imprinted material capacity for MTD was only $31.76 \mu \mathrm{g} \mathrm{g}^{-1}$, which indicates the advantage of using imprinted adsorbent in the extraction process. The calibration curve that investigated using solutions with MTD concentrations of $0.5,5,10,15,20$, $25,50,75,90,95,100,105,115$ and $120 \mu \mathrm{g} \mathrm{mL}^{-1}$ was linear in the range of about 15 to $100 \mu \mathrm{g} \mathrm{mL} \mathrm{m}^{-1}$ with coefficient of determination $\left(\mathrm{R}^{2}\right)$ of 0.991 . The limit of the detection of MTD using UV-Vis spectrophotometry was $2.31 \mu \mathrm{g} \mathrm{mL}^{-1}$.

In order to investigate the use of developed method, it was applied to determine the MTD in spiked and non-spiked pharmaceutical formulations. The results presented in Table 3, compared favorably to the combination of proposed SPE procedure with HPLC-UV-Vis and the method of HPLC-UV-Vis (as standard method) alone. Analysis of the results using the $t$-test and $F$-test showed no statistically significant difference between the performances of these methods for $95 \%$ confidence level. In each method, five

Table 2. Evaluation of interference of co-existing foreign and structurally similar substances on the recoveries (\%) of MTD

\begin{tabular}{|c|c|c|c|c|c|c|c|c|c|c|c|c|c|c|}
\hline \multirow{2}{*}{ Interferent } & \multicolumn{14}{|c|}{ Concentration of interferent $/\left(\times 1000 \mu \mathrm{g} \mathrm{mL}^{-1}\right)$} \\
\hline & 0.7 & 1.05 & 1.4 & 3.5 & 4.2 & 7 & 10.5 & 11.2 & 21 & 28 & 28.7 & 35 & 49 & 49.7 \\
\hline $\mathrm{NO}_{3}^{-}, \mathrm{Cl}^{-}, \mathrm{SO}_{4}^{2-}, \mathrm{Na}^{+}, \mathrm{K}^{+}, \mathrm{Ca}^{2+}$ & - & - & - & 98.20 & - & 97.32 & - & 96.48 & - & 93.79 & - & 93.90 & 92.35 & 87.93 \\
\hline $\mathrm{PO}_{4}^{3-}, \mathrm{CO}_{3}^{2-}, \mathrm{Fe}^{3+}, \mathrm{Mg}^{2+}$ & - & - & 98.55 & - & 96.42 & - & 97.65 & - & 94.62 & 92.85 & 85.28 & - & - & - \\
\hline Uric acid, glucose, sucrose & 96.40 & - & 95.35 & - & 93.29 & - & 92.47 & 83.91 & - & - & - & - & - & - \\
\hline Dopamine & 93.17 & - & 91.23 & 91.97 & 82.66 & - & - & - & - & - & - & - & - & - \\
\hline Epinephrine & 91.53 & 90.14 & 81.63 & - & - & - & - & - & - & - & - & - & - & - \\
\hline
\end{tabular}

Average percentages of MTD recoveries for five measurements in each concentration level of interferent. Sample conditions: volume, 5 mL; solvent, methanol; MTD concentration, $70 \mu \mathrm{g} \mathrm{mL}^{-1}$. SPE conditions: amount of adsorbents in SPE column, $300 \mathrm{mg}$; sample flow rate, $5 \mathrm{~mL}$ min ${ }^{-1}$; elution flow rate, $1 \mathrm{~mL} \mathrm{~min}^{-1}$; all determinations were acomplished with UV-Vis method at $\lambda 280 \mathrm{~nm}$. 
measurements were performed. As Table 3 and Figure 7 show, the methods in which the proposed SPE process was used, the recoveries of samples were improved in the range from 94.7 to $98.3 \%$. The relative standard deviation (RSD) was less than $5.69 \%$. The results showed that the imprinted silica adsorbent can be directly used to adsorb and determine the MTD in pharmaceutical samples. Sustainable features of the adsorbent allowed that it could be used for more than 50 cycles with recovery average decrease less than $8.6 \%$.

The validation protocol explains the design of the validation study. Its purpose is to provide information about which features are tested during the study, how the experiments are carried out and the results to be calculated. The ICH (International Conference on Harmonisation) guidelines ${ }^{31}$ state that "the list of features should typically be considered for the analytical procedures, but exceptional occasions should be considered on an individual basis".
The lack of specificity for an analytical procedure can be compensated by adding a second analytical method. This compensation is in accordance with the FDA (Food and Drug Administration) guidelines. ${ }^{31}$ Due to proof of the robustness and linearity of calibration model, it can be concluded that the proposed analytical procedure complies with the ICH protocol. Acceptable regression line and coefficient of determination, as well as successful statistical $t$ and $F$-tests with good RSDs are the reasons of this accordance.

\section{Conclusions}

In this new and simple method for the synthesis of molecularly MTD-imprinted sorbent, the potential of surface molecular imprinting technique has been demonstrated. As an SPE sorbent, the proposed material showed high capacity to adsorb and determine MTD in pharmaceutical products. Table 4 compares the obtained results of MTD adsorption

Table 3. Determination of MTD in commercial pharmaceutical preparation (tablet)

\begin{tabular}{|c|c|c|c|c|c|c|c|c|c|c|c|c|c|c|}
\hline \multirow{4}{*}{$\begin{array}{l}\text { Label value / } \\
\left(\mathrm{mg} \text { unit } \mathrm{t}^{-1}\right)\end{array}$} & \multirow{4}{*}{$\begin{array}{l}\text { Spiked } \\
\text { value / } \\
\mathrm{mg}\end{array}$} & \multicolumn{11}{|c|}{ Tested method } & \multirow{3}{*}{\multicolumn{2}{|c|}{$\begin{array}{c}\text { Evaluation of } \\
\text { ANOVA (three } \\
\text { methods) }\end{array}$}} \\
\hline & & \multirow{3}{*}{$\begin{array}{l}\text { HPLC-UV-Vis } \\
\text { (as standard) }\end{array}$} & \multicolumn{5}{|c|}{ Proposed method } & \multicolumn{5}{|c|}{ Proposed method-HPLC-UV-Vis } & & \\
\hline & & & \multirow{2}{*}{$\begin{array}{l}\text { Determined } \\
\text { value / mg }\end{array}$} & \multicolumn{2}{|c|}{$F$-test } & \multicolumn{2}{|c|}{$t$-test } & \multirow{2}{*}{$\begin{array}{l}\text { Determined } \\
\text { value / mg }\end{array}$} & \multicolumn{2}{|c|}{$F$-test } & \multicolumn{2}{|c|}{$t$-test } & & \\
\hline & & & & $F_{\text {cal. }}$ & $F_{0.975}(4,4)$ & $t_{\text {cal. }}$ & $t_{0.975,8}$ & & $F_{\text {cal. }}$ & $F_{0.975}(4,4)$ & $t_{\text {cal. }}$ & $t_{0.975,8}$ & $F_{\text {cal. }}$ & $F_{0.95}(2,8)$ \\
\hline \multirow{4}{*}{250.0} & 0 & $238.7(3.9)$ & $244.9(5.6)$ & 2.06 & 9.60 & 2.033 & 2.306 & $241.4(4.5)$ & 1.33 & 9.60 & 1.039 & 2.306 & 3.84 & 4.46 \\
\hline & 25 & $261.2(3.1)$ & $267.8(5.9)$ & 3.62 & 9.60 & 2.200 & 2.306 & $264.9(5.1)$ & 2.71 & 9.60 & 1.370 & 2.306 & 4.15 & 4.46 \\
\hline & 50 & $287.5(4.6)$ & $294.3(6.1)$ & 1.76 & 9.60 & 2.000 & 2.306 & $290.5(5.7)$ & 1.54 & 9.60 & 0.909 & 2.306 & 3.62 & 4.46 \\
\hline & 100 & $339.3(4.2)$ & $345.5(4.8)$ & 1.31 & 9.60 & 2.214 & 2.306 & $342.1(4.9)$ & 1.36 & 9.60 & 0966 & 2.306 & 3.59 & 4.46 \\
\hline
\end{tabular}

Average of five measurements with RSD (\%) in parenthesis. Sample conditions: volume, $5 \mathrm{~mL}$; solvent, methanol. SPE (solid phase extraction) conditions:

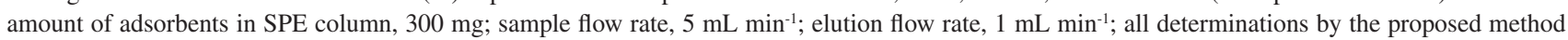
were acomplished with UV-Vis spectrophotometry at $\lambda 280 \mathrm{~nm}$. HPLC condition: mobile phase, $92+8$ methanol-phosphate buffer; $\mathrm{pH}, 2.88$; flow rate, $1.5 \mathrm{~mL} \mathrm{~min}^{-1}$; detection by UV-Vis spectrophotometry at $\lambda 280 \mathrm{~nm}$.
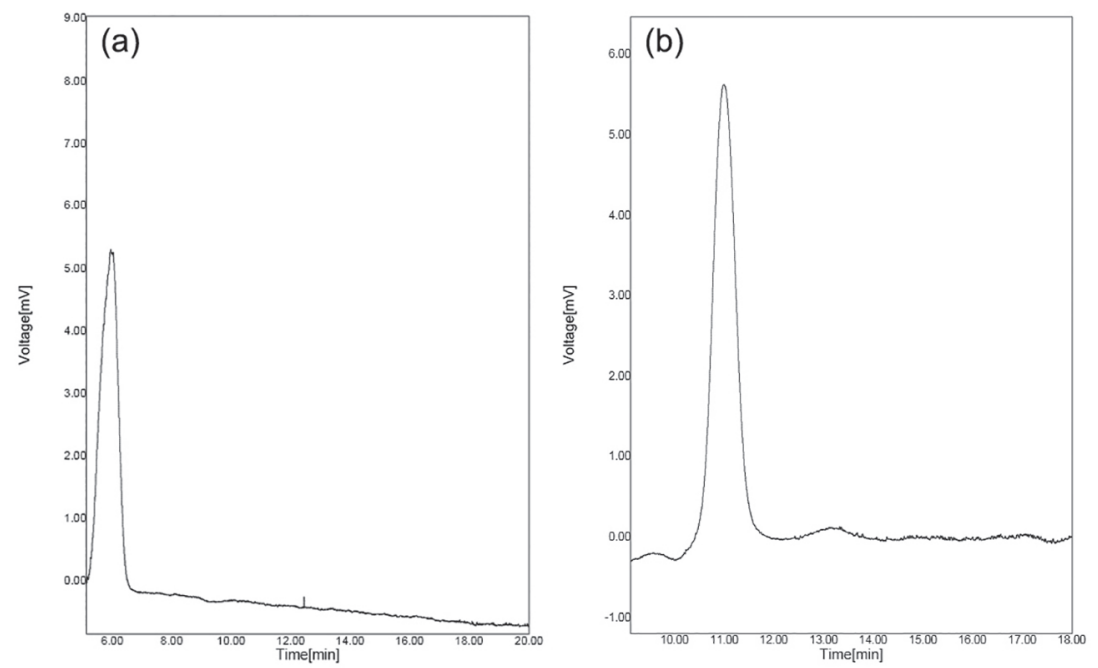

Figure 7. Chromatograms of the MTD pharmaceutical samples; (a) direct injection of the pharmaceutical sample solution; (b) eluate obtained from surface imprinted SPE column. (HPLC condition: mobile phase, $92+8$ methanol-phosphate buffer; $\mathrm{pH}, 2.88$; flow rate, $1.5 \mathrm{~mL} \mathrm{~min}^{-1}$; detection by UV-Vis spectrophotometry at $280 \mathrm{~nm}$ ). 
Table 4. Comparison of the results of various reported studies on different separation and detection methods for determination of methyldopa and structurally similar compounds

\begin{tabular}{|c|c|c|c|c|c|c|c|c|c|c|}
\hline \multirow[b]{2}{*}{$\begin{array}{l}\text { Separation } \\
\text { or extraction } \\
\text { process }\end{array}$} & \multirow[b]{2}{*}{$\begin{array}{c}\text { Stationary } \\
\text { or solid } \\
\text { phase }\end{array}$} & \multirow[b]{2}{*}{$\begin{array}{l}\text { Detection } \\
\text { method }\end{array}$} & \multirow[b]{2}{*}{ Analyte } & \multirow[b]{2}{*}{$\begin{array}{c}\text { Sample } \\
\text { solution } \\
\mathrm{pH}\end{array}$} & \multicolumn{4}{|c|}{ Analytical figures of merit } & \multirow[b]{2}{*}{$\begin{array}{l}\text { Tested real } \\
\text { sample }\end{array}$} & \multirow[b]{2}{*}{ Reference } \\
\hline & & & & & $\begin{array}{c}\text { Linear } \\
\text { range / } \\
\left(\mu \mathrm{g} \mathrm{mL}^{-1}\right)\end{array}$ & $\begin{array}{c}\text { Coefficient of } \\
\text { determination } \\
\left(\mathrm{R}^{2}\right)\end{array}$ & $\begin{array}{c}\text { LOD / } \\
\left(\mu \mathrm{g} \mathrm{mL}^{-1}\right)\end{array}$ & $\operatorname{RSD} / \%$ & & \\
\hline HPLC & nucleosil 7 C18 & fluorescence & alpha-methyldopa & 3.2 & $0.01-3$ & 0.999 & 0.01 & 2.79 & plasma & Rona et $a ._{.}^{32}$ \\
\hline HPLC & ODS & fluorescence & methyldopa & 2.3 & $0.02-5$ & 0.9976 & 0.008 & 4.12 & human serum & Bahrami et al. ${ }^{33}$ \\
\hline $\mathrm{LC}$ & $\mathrm{C} 18$ & MS/MS & dopamine & 8.5 & $0.001-0.4$ & - & 0.00005 & $<5$ & human plasma & Merbel et $a l .^{34}$ \\
\hline HPLC & $\mathrm{C} 18$ & ED & $\begin{array}{l}\text { 3-O-methyldopa } \\
\text { and structurally } \\
\text { similar }\end{array}$ & 2.88 & $0.2-10$ & 0.9976 & 0.004 & 5.64 & plasma & $\begin{array}{l}\text { Bugamelli } \\
\text { et al. }{ }^{35}\end{array}$ \\
\hline HPLC & $\mathrm{C} 8$ & MS/MS & $\begin{array}{l}\text { 3-O-methyldopa } \\
\text { and structurally } \\
\text { similar }\end{array}$ & - & $0.01-1$ & 0.98 & 0.007 & 11.3 & human plasma & Ribeiro et al. ${ }^{36}$ \\
\hline HPLC & $\begin{array}{c}\text { single protein- } \\
\text { coated TSK gel } \\
\text { ODS-80 TM }\end{array}$ & fluorescence & methyldopa & 2.4 & $0.1-30$ & 0.9996 & 0.027 & ca. 1 & human serum & Emara et al..$^{37}$ \\
\hline SPE & $\begin{array}{c}\text { surface } \\
\text { imprinted } \\
\text { silica gel }\end{array}$ & $\begin{array}{c}\text { UV-Vis } \\
\text { spectrophotometry }\end{array}$ & methyldopa & ca. 8 & $15-100$ & 0.991 & 2.31 & 5.69 & $\begin{array}{l}\text { pharmaceutical } \\
\text { formulation }\end{array}$ & present study \\
\hline
\end{tabular}

HPLC: high-performance liquid chromatography; SPE: solid phase extraction; MS/MS: tandem mass spectrometry; ED: electrochemical detection; LOD: limit of detection; RSD: relative standard deviation.

capacity and other operating conditions of present study with the literature. The proposed approach results in a simple, inexpensive and accurate analytical technique to determine the MTD in commercial pharmaceutical samples with satisfactory recoveries. Moreover, it does not need to remove traditional components present in the pharmaceutical formulation because they were found not to interfere with the determination of MTD.

\section{Acknowledgments}

The Laboratory of Chemistry Department, College of Science, Islamic Azad University, Tabriz Branch, supported this work.

\section{References}

1. Turiel, E.; Martin-Esteban, A.; Anal. Chim. Acta 2010, 668, 87.

2. Gupta, R.; Kumar, A.; Biotechnol. Adv. 2008, 26, 533.

3. Gao, R.; Kong, X.; Su, F.; He, X.; Chen, L.; Zhang, Y.; J. Chromatogr. A 2010, 1217, 8095.

4. Su, S.; Zhang, M.; Li, B.; Zhang, H.; Dong, X.; Talanta 2008, $76,1141$.

5. Liu, H.; Liu, C.; Yang, X.; Zeng, S.; Xiong, Y.; Xu, W.; Anal. Chim. Acta 2008, 628, 87.

6. Jiang, X.; Tian, W.; Zhao, C.; Zhang, H.; Liu, M.; Talanta 2007, $72,119$.

7. Say, R.; Erdem, M.; Ersoz, A.; Turk, H.; Denizli, A.; Appl. Catal. A 2005, 286, 221.
8. Ko, D. Y.; Lee, H. J.; Jeong, B.; Macromol. Rapid Commun. 2006, 27, 1367.

9. Bui, B. T. S.; Haupt, K.; Anal. Bioanal. Chem. 2010, 398, 2481.

10. Fang, G. Z.; Tan, J.; Yan, X. P.; Anal. Chem. 2005, 77, 1734.

11. Chang, X.; Jiang, N.; Zheng, H.; He, Q.; Hu, Z.; Zhai, Y.; Cui, Y.; Talanta 2007, 71, 38.

12. Zhang, N.; Hu, B.; Huang, C.; Anal. Chim. Acta 2007, 597, 12.

13. Ansell, R. J.; Krij, D.; Mosbach, K.; Curr. Opin. Biotechnol. 1996, 7, 89.

14. Kriz, D.; Mosbach, K.; Anal. Chim. Acta 1995, 300, 71.

15. Abdul Raof, S. F.; Mohamad, S.; Abas, M. R.; Int. J. Mol. Sci. 2013, 14, 5952.

16. British Pharmacopoeia, British Pharmacopoeia Commission, Stationery Office, London, 2009.

17. The United States Pharmacopoeia, $24^{\text {th }}$ ed.; The United States Pharmacopoeial Convention: Rockville, Maryland, USA, 2000.

18. Salem, F. B.; Anal. Lett. 1993, 26, 1959.

19. Salem, F. B.; Anal. Lett. 1993, 26, 281.

20. Garrido, M. E.; Lima, J. L. F. C.; Delerue-Mattos, C.; J. Pharm. Biomed. Anal. 1997, 15, 845.

21. Sharma, C.; Mohanty, S.; Kumar, S.; Rao, N. J.; Analyst 1996, 121, 1963.

22. Parsons, L. H.; Kerr, T. M.; Weiss, F.; J. Chromatogr. B 1998, 709,35 .

23. Nozaki, O.; Iwaeda, T.; Moriyama, H.; Kato, Y.; Luminescence 1999, 14, 123.

24. Kozminski, K. D.; Gutman, D. A.; Davila, V.; Sulzer, D.; Ewing, A. G.; Anal. Chem. 1998, 70, 3123. 
25. Gowda, B. G.; Melwanki, M. B.; Ramappa, S.; Anal. Sci. 2001, $17,533$.

26. Nagaraja, P.; Vasantha, R. A.; Sunitha, K. R.; Talanta 2001, 55, 1039.

27. Salem, F. B.; Talanta 1987, 34, 810.

28. Saber Tehrani, M.; Vardini, M. T.; Abroomand Azar, P.; Husain, S. W.; Chin. J. Chem. 2010, 28, 647.

29. Jal, P. K.; Patel, S.; Mishra, B. K.; Talanta 2004, 62, 1005.

30. Zhang, N.; Suleiman, J. S.; He, M.; Hu, B.; Talanta 2008, 75, 536.

31. McPolin, O.; Validation of Analytical Methods for Pharmaceutical Analysis; Mourne Training Services: Warrenpoint, Northern Ireland, UK, 2009.

32. Rona, K.; Ary, K.; Gachalyi, B.; Klebovich, I.; J. Chromatogr. A 1996, 730, 125.
33. Bahrami, G.; Kiani, A.; Mirzaeei, S.; J. Chromatogr. B 2006, 832, 197.

34. Merbel, N. C. V. D.; Hendriks, G.; Imbos, R.; Tuunainen, J.; Rouru, J.; Nikkanen, H.; Bioanalysis 2011, 3, 1949.

35. Bugamelli, F.; Marcheselli, C.; Barba, E.; Raggi, M. A.; J. Pharm. Biomed. Anal. 2011, 54, 562.

36. Ribeiro, R. P.; Gasparetto, J. C.; Vilhena, R. D. O.; Francisco, T. M. G. D.; Martins, C. A.; Cardoso, M. A.; Pontarolo, R.; Carvalho, K. A. D.; Bioanalysis 2015, 7, 207.

37. Emara, S.; Masujima, T.; Zarad, W.; Kamal, M.; Fouad, M.; El-Bagary, R.; J. Chromatogr. Sci. 2015, 53, 1353.

Submitted: May 21, 2017

Published online: July 24, 2017 